\title{
Reduction of hydrazines to amines with low-valent titanium reagent
}

\author{
Fang Ren, Yan Zhang, Lan Hu, and Meiming Luo* \\ Key Laboratory of Green Chemistry \& Technology of Ministry of Education, College of \\ Chemistry, Sichuan University, Chengdu 610064, People's Republic of China \\ E-mail:luomm@scu.edu.cn
}

DOI: $\underline{\text { http://dx.doi.org/10.3998/ark.5550190.0014.313 }}$

\begin{abstract}
The $\mathrm{N}, \mathrm{N}$ bond cleavage in hydrazines to amines via low-valent titanium reagent prepared in situ by treatment of $\mathrm{TiCl}_{4}$ with $\mathrm{Mg}$ powder in THF or $\mathrm{CH}_{2} \mathrm{Cl}_{2}-\mathrm{Et}_{2} \mathrm{O}$ is described. The reaction proceeds smoothly under mild conditions to afford amines in good to excellent yields with diverse functional group tolerance such as chloride, methoxyl, benzyloxyl, ester, acyl, as well as $\mathrm{C}, \mathrm{C}$ double bonds and benzyl-nitrogen bonds.
\end{abstract}

Keywords: Hydrazine, amine, N,N bond cleavage, low-valent titanium reagent

\section{Introduction}

Amines constitute an important class of compounds in chemistry and biology. They are frequently encountered as drugs in the pharmaceutical industry, pesticides for crop protection and target molecules in total synthesis. ${ }^{1}$ Among various methods for the synthesis of amines, hydrazines often appear as key intermediates. ${ }^{2-12}$ Remarkable examples are the addition of alkylzinc reagent to arylazo tosylates, ${ }^{12}$ electrophilic addition of $\alpha$-diazoesters with ketones,${ }^{13}$ the addition of carbon nucleophiles to azodicarboxylates ${ }^{14}$ and acylhydrazonium salts, ${ }^{15}$ the anionic ${ }^{8,16}$ or radical ${ }^{17}$ additions to the $\mathrm{C}=\mathrm{N}$ bond of hydrazones, the cross-coupling of ketones with hydrazones, ${ }^{18}$ the addition of $N$-aminolactams to Michael acceptors, ${ }^{10,19}$ the aza-Michael addition of hydrazines to electrophilic alkenes, ${ }^{20}$ the radical cyclization of $N$-allyl- $\alpha$ perchlorohydrazides, ${ }^{21}$ and the 1,3-dipolar cycloaddition of azomethine imines to dipolarophiles. ${ }^{22}$ These examples clearly show the significance of $\mathrm{N}, \mathrm{N}$ bond cleavage in organic synthesis. Although a number of methods have been developed for $\mathrm{N}, \mathrm{N}$ bond cleavage in hydrazine-based substrates and they give satisfactory results in general, limitations and difficulties are frequently encountered in many cases, mainly related to harsh acidic or basic reaction conditions, incompatibility with some functionalities, requirement of activating groups, and in some cases the lack of reactivity. ${ }^{6}$ For example, $\mathrm{Zn} / \mathrm{H}^{+}$reduction requires acidic 
condition, ${ }^{11}$ dissolving metal reduction generates basic condition, ${ }^{4,23}$ hydroboration ${ }^{24}$ is incompatible with $\mathrm{C}=\mathrm{C}$ bond, the metal-catalyzed hydrogenolysis may cause hydrogenation of $\mathrm{C}=\mathrm{C}$ bond and hydrogenolysis of benzyloxyl protecting group before the reductive cleavage of hydrazine $\mathrm{N}-\mathrm{N}$ bonds, ${ }^{6,8}$ the oxidative cleavage ${ }^{6,7}$ and $\mathrm{SmI}_{2}$-reductive cleavage ${ }^{8,10}$ usually need an activating acyl group on at least one of the hydrazine nitrogens, and the reaction with 2naphthols restricts to $N, N$-disubstituted hydrazines at present stage. ${ }^{25}$ Recently, we reported the reductive cleavage of the $\mathrm{N}, \mathrm{N}$ bond in hydrazines with aqueous titanium(III) trichloride solution. ${ }^{26}$ Aqueous solution and heating involved in the method reduce its general use.

Use of a low-valent titanium reagent as a powerful electron donor has been reported to accomplish certain deoxygenations such as reductive coupling of carbonyl compounds, ${ }^{27}$ and reduction of sulphoxides, epoxides, bromohydrins, and cyanohydrins. ${ }^{28}$ So far as we know, use of low-valent titanium reagents has not been reported for the reductive cleavage of $\mathrm{N}$, N bonds in hydrazines to produce amines. Reports demonstrated that titanium(II) reagents can serve as the reductant for transformation of $N$-nitrosoamines to hydrazines, ${ }^{29}$ which indicates the titanium(II) reagent did not reduce hydrazines to amines at room temperature. We hypothesize that the powerful reductivity of titanium(0) reagent which is usually prepared in situ with an excess amount of reductant in nonaqueous organic solvent could be exploited to reduce hydrazine to amine under mild conditions, thus overcoming the difficulties encountered in previously reported methods. Herein we report the readily N,N bond cleavage of hydrazines in THF or $\mathrm{CH}_{2} \mathrm{Cl}_{2}$-ether with a wide range of functional group tolerance under mild conditions by low-valent reagent prepared in situ by reducing $\mathrm{TiCl}_{4}$ with excess magnesium powder.

\section{Results and Discussion}

A number of agents can reduce $\mathrm{TiCl}_{4}$ to low-valent titanium reagent, including $\mathrm{LiAlH}_{4}$, alkaline metal, $\mathrm{Zn}$ and $\mathrm{Mg}$ powder. ${ }^{27}$ For simplicity and convenience, our attention turned to $\mathrm{Zn}$ and $\mathrm{Mg}$ powder. Because $\mathrm{Zn}$ reacted sluggishly with $\mathrm{TiCl}_{4}, \mathrm{Mg}$ powder was finally employed for the preparation of low-valent titanium reagent from $\mathrm{TiCl}_{4}$ in this study. 
Table 1. Reduction of phenylhydrazine to aniline with low-valent titanium reagent ${ }^{a}$

\begin{tabular}{llll} 
& & & THF, r.t. $(\mathrm{Ar})$ \\
\hline Entry & Hydrazine/TiCl$/ \mathrm{Mg}(\mathrm{mol})$ & Time $(\mathrm{h})$ & Yield $(\%)^{b}$ \\
\hline 1 & $1: 1: 2.5$ & 1 & 93 \\
2 & $1: 4: 10$ & 0.3 & 94 \\
3 & $1: 0.4: 2.5$ & 2 & 92 \\
4 & $1: 0.2: 2.5$ & 4 & 90 \\
5 & $1: 0.1: 2.5$ & 12 & 71 \\
6 & $1: 0: 2.5$ & 12 & 0 \\
\hline
\end{tabular}

${ }^{a} 10 \mathrm{mmol}$ of phenylhydrazine was used. ${ }^{b}$ Average isolated yield of two runs.

As shown in Table 1, transformation of phenylhydrazine to aniline was chosen as a model reaction to optimize the reaction conditions. To avoid interference of air oxidation, the reaction was performed under an argon atmosphere. Low-valent titanium reagent was firstly prepared by stirring the mixture of $\mathrm{TiCl}_{4}$ and $\mathrm{Mg}$ powder in THF for $2 \mathrm{~h}$ at room temperature. The molar ratio of $\mathrm{TiCl}_{4}$ to $\mathrm{Mg}$ was kept less than 1:2 to ensure the reduction of $\mathrm{TiCl}_{4}$. Then phenylhydrazine was added, and the reduction was performed at room temperature and monitored by TLC. Different molar ratios of hydrazine/ $/ \mathrm{TiCl}_{4} / \mathrm{Mg}$ were explored, and we found that the molar ratio affected the product yield and reaction time significantly. When the molar ratio of phenylhydrazine/ $\mathrm{TiCl}_{4} / \mathrm{Mg}$ was 1:1:2.5, the reaction was complete in $1 \mathrm{~h}$, affording aniline in $93 \%$ yield (Table 1, entry 1 ). Increasing the amount of $\mathrm{TiCl}_{4}$ from a phenylhydrazine/ $\mathrm{TiCl} / \mathrm{Mg}$ molar ratio of 1:1:2.5 to $1: 4: 10$ led to completion of the reaction within $20 \mathrm{~min}$, albeit the yield of aniline was not improved significantly (Table 1, entry 2). Interestingly, when the amount of $\mathrm{TiCl}_{4}$ was reduced to phenylhydrazine/ $\mathrm{TiCl}_{4} / \mathrm{Mg}$ molar ratios of 1:0.4:2.5 and 1:0.2:2.5, the reaction went smoothly as well, giving aniline in $92 \%$ yield in $2 \mathrm{~h}$ (Table 1, entry 3 ) and $90 \%$ in $4 \mathrm{~h}$ (Table 1, entry 4), respectively. When the amount of $\mathrm{TiCl}_{4}$ was further decreased to a phenylhydrazine/ $\mathrm{TiCl}_{4} / \mathrm{Mg}$ molar ratio of 1:0.1:2.5, phenylhydrazine was not completely consumed even after $12 \mathrm{~h}$ based on TLC monitoring, and aniline was obtained in $71 \%$ yield (Table 1, entry 5). A control reaction was run, and when $\mathrm{TiCl}_{4}$ was not added, no reaction occurred (Table 1, entry 6). Thus the optimized reaction conditions involved use of a hydrazine/ $\mathrm{TiCl}_{4} / \mathrm{Mg}$ molar ratio of 1:0.4:2.5 in anhydrous THF under argon atmosphere at ambient temperature.

With the effective reaction conditions in hand, we next investigated the generality of the reaction with respect to hydrazines. As shown in Table 2, monosubstituted hydrazines (Table 2, entries 1-6), N,N-disubstituted hydrazines (Table 2, entries 7-15), symmetrical and unsymmetrical $N, N^{\prime}$-disubstituted hydrazines (Table 2, entries 16-18) could be reductively 
dissociated to the corresponding primary and secondary amines by low-valent titanium reagent in $\mathrm{THF}$ at room temperature with a hydrazine/ $\mathrm{TiCl}_{4} / \mathrm{Mg}$ molar ratio of 1:0.4:2.5; the yields were generally excellent.

Table 2. Reduction of hydrazines with low-valent titanium reagent in $\mathrm{THF}^{a}$

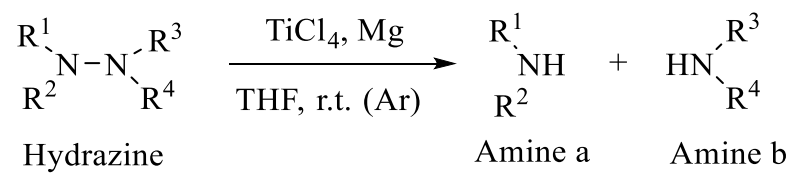

\begin{tabular}{|c|c|c|c|}
\hline Entry & Substituent & Amine a, yield $(\%)^{b}$ & Amine $\mathrm{b}$, yield $(\%)^{b}$ \\
\hline 1 & $\mathrm{R}^{1}=$ phenyl, $\mathrm{R}^{2}=\mathrm{R}^{3}=\mathrm{R}^{4}=\mathrm{H}$ & $\mathbf{1 a}, 92$ & $\mathrm{NH}_{3},---$ \\
\hline 2 & $\mathrm{R}^{1}=2$-naphthyl, $\mathrm{R}^{2}=\mathrm{R}^{3}=\mathrm{R}^{4}=\mathrm{H}$ & $\mathbf{2 a}, 90$ & $\mathrm{NH}_{3},---$ \\
\hline 3 & $\mathrm{R}^{1}=2$-methoxyphenyl, $\mathrm{R}^{2}=\mathrm{R}^{3}=\mathrm{R}^{4}=\mathrm{H}$ & $\mathbf{3 a}, 71$ & $\mathrm{NH}_{3},---$ \\
\hline 4 & $\mathrm{R}^{1}=4$-chlorophenyl, $\mathrm{R}^{2}=\mathrm{R}^{3}=\mathrm{R}^{4}=\mathrm{H}$ & $\mathbf{4 a}, 74$ & $\mathrm{NH}_{3},---$ \\
\hline 5 & $\begin{array}{l}\mathrm{R}^{1}=4 \text {-ethoxycarbonylphenyl, } \\
\mathrm{R}^{2}=\mathrm{R}^{3}=\mathrm{R}^{4}=\mathrm{H}\end{array}$ & $\mathbf{5 a}, 82$ & $\mathrm{NH}_{3},---$ \\
\hline 6 & $\mathrm{R}^{1}=$ cyclohexyl, $\mathrm{R}^{2}=\mathrm{R}^{3}=\mathrm{R}^{4}=\mathrm{H}$ & $\mathbf{6 a}, 72$ & $\mathrm{NH}_{3},---$ \\
\hline 7 & $\mathrm{R}^{1} \mathrm{R}^{2} \mathrm{~N}=1$-piperidinyl, $\mathrm{R}^{3}=\mathrm{R}^{4}=\mathrm{H}$ & $7 \mathbf{a}, 74$ & $\mathrm{NH}_{3},---$ \\
\hline 8 & $\mathrm{R}^{1}=\mathrm{R}^{2}=$ isobutyl, $\mathrm{R}^{3}=\mathrm{R}^{4}=\mathrm{H}$ & $\mathbf{8 a}, 57$ & $\mathrm{NH}_{3},---$ \\
\hline 9 & $\mathrm{R}^{1}=\mathrm{R}^{2}=$ cyclohexyl, $\mathrm{R}^{3}=\mathrm{R}^{4}=\mathrm{H}$ & $\mathbf{9 a}, 70$ & $\mathrm{NH}_{3},---$ \\
\hline 10 & $\mathrm{R}^{1}=$ phenyl, $\mathrm{R}^{2}=$ cyclohexyl, $\mathrm{R}^{3}=\mathrm{R}^{4}=\mathrm{H}$ & $\mathbf{1 0 a}, 76$ & $\mathrm{NH}_{3},---$ \\
\hline 11 & $\mathrm{R}^{1}=$ phenyl, $\mathrm{R}^{2}=$ allyl, $\mathrm{R}^{3}=\mathrm{R}^{4}=\mathrm{H}$ & $\mathbf{1 1 a}, 76$ & $\mathrm{NH}_{3},---$ \\
\hline 12 & $\mathrm{R}^{1}=$ phenyl, $\mathrm{R}^{2}=$ benzyl, $\mathrm{R}^{3}=\mathrm{R}^{4}=\mathrm{H}$ & $\mathbf{1 2 a}, 72$ & $\mathrm{NH}_{3},---$ \\
\hline 13 & $\mathrm{R}^{1}=$ phenyl, $\mathrm{R}^{2}=\mathrm{n}$-heptyl, $\mathrm{R}^{3}=\mathrm{R}^{4}=\mathrm{H}$ & $\mathbf{1 3 a}, 75$ & $\mathrm{NH}_{3},---$ \\
\hline 14 & $\mathrm{R}^{1}=2$-naphthyl, $\mathrm{R}^{2}=$ methyl, $\mathrm{R}^{3}=\mathrm{R}^{4}=\mathrm{H}$ & $\mathbf{1 4 a}, 72$ & $\mathrm{NH}_{3},---$ \\
\hline 15 & $\mathrm{R}^{1}=\mathrm{R}^{2}=$ phenyl, $\mathrm{R}^{3}=\mathrm{R}^{4}=\mathrm{H}$ & 15a, 90 & $\mathrm{NH}_{3},---$ \\
\hline 16 & $\mathrm{R}^{1}=\mathrm{R}^{3}=$ phenyl, $\mathrm{R}^{2}=\mathrm{R}^{4}=\mathrm{H}$ & 1a, 91 & \\
\hline 17 & $\mathrm{R}^{1}=\mathrm{R}^{3}=4$-methylphenyl, $\mathrm{R}^{2}=\mathrm{R}^{4}=\mathrm{H}$ & $\mathbf{1 7 a}, 91$ & \\
\hline 18 & $\mathrm{R}^{1}=$ phenyl, $\mathrm{R}^{3}=$ benzyl, $\mathrm{R}^{2}=\mathrm{R}^{4}=\mathrm{H}$ & 1a, 76 & $18 b, 84$ \\
\hline $19^{c}$ & $\mathrm{R}^{1}=\mathrm{R}^{3}=$ phenyl, $\mathrm{R}^{2}=\mathrm{R}^{4}=$ methyl & 19a, 82 & \\
\hline $20^{c}$ & $\mathrm{R}^{1}=\mathrm{R}^{3}=$ phenyl, $\mathrm{R}^{2}=$ allyl, $\mathrm{R}^{4}=$ methyl & 11a, 77 & $19 a, 83$ \\
\hline $21^{c}$ & $\mathrm{R}^{1}=\mathrm{R}^{3}=$ phenyl, $\mathrm{R}^{2}=\mathrm{R}^{4}=$ benzyl & 12a, 73 & \\
\hline $22^{c}$ & $\mathrm{R}^{1}=\mathrm{R}^{2}=\mathrm{R}^{3}=\mathrm{R}^{4}=$ phenyl & 15a, 80 & \\
\hline
\end{tabular}

$a$ Reaction conditions: THF as the solvent, hydrazine $(10 \mathrm{mmol})$, hydrazine $/ \mathrm{TiCl}_{4} / \mathrm{Mg}=$ 1:0.4:2.5, r.t., 2-6 h. ${ }^{b}$ Yield of isolated product. The yield of $\mathrm{NH}_{3}$ was not determined. ${ }^{\mathrm{c}}$ hydrazine $/ \mathrm{TiCl}_{4} / \mathrm{Mg}=1: 4: 10,60^{\circ} \mathrm{C}, 4-6 \mathrm{~h}$. 
For $N, N, N^{\prime}, N^{\prime}$-tetrasubstituted hydrazines (Table 2, entries 19-22), however, a hydrazine $/ \mathrm{TiCl}_{4} / \mathrm{Mg}$ molar ratio of 1:4:10 and higher reaction temperature of $60{ }^{\circ} \mathrm{C}$ were required for complete conversion of substrates, which was probably due to the steric hindrance of tetrasubstituted hydrazines. Alkylhydrazines (Table 2, entries 6-9) underwent the reaction as well as arylhydrazines. It was noted that common functional groups such as methoxyl (Table 2, entry 3), chloride (Table 2, entry 4), ester (Table 2, entry 5), C,C double bonds (Table 2, entries 11 and 20) which are usually susceptible to hydrogenation and hydroboration reactions, and benzyl-nitrogen bonds (Table 2, entries 12, 18 and 21) were all well tolerated in the reaction.

Interestingly, we found that solvent made important impact on the reaction. Acylhydrazines gave complex products by TLC monitoring when the reduction was carried out in THF. Fortunately, when performed in the mixture solvent of $\mathrm{CH}_{2} \mathrm{Cl}_{2} / \mathrm{Et}_{2} \mathrm{O}$ (4:1, v/v) at room temperature with a hydrazine/ $\mathrm{TiCl}_{4} / \mathrm{Mg}$ molar ratio of 1:4:10, acylhydrazines including benzyloxycarbonyl (Table 3, entry 4) underwent the reaction furnishing the desired product in good yields (Table 3, entries 1-4).

Table 3. Reduction of hydrazines with low-valent titanium reagent in $\mathrm{CH}_{2} \mathrm{Cl}_{2}-\mathrm{Et}_{2} \mathrm{O}^{a}$

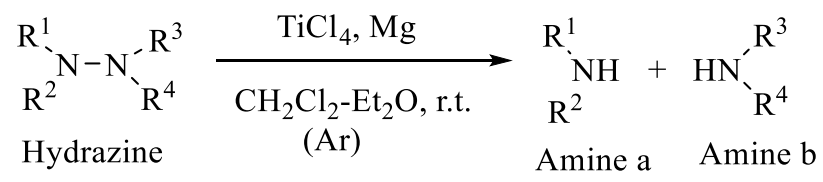

\begin{tabular}{llll}
\hline Entry & Substituent & Amine a, yield $(\%)^{b}$ & Amine b, yield $(\%)^{b}$ \\
\hline 1 & $\mathrm{R}^{1}=$ benzoyl, $\mathrm{R}^{2}=\mathrm{R}^{3}=\mathrm{R}^{4}=\mathrm{H}$ & $\mathbf{2 3 a}, 75$ & $\mathrm{NH}_{3}$ \\
2 & $\mathrm{R}^{1}=$ phenyl, $\mathrm{R}^{3}=$ acetyl, $\mathrm{R}^{2}=\mathrm{R}^{4}=\mathrm{H}$ & $\mathbf{1 a}, 74$ & $\mathbf{2 4 b}, 63$ \\
3 & $\mathrm{R}^{1}=\mathrm{R}^{3}=$ benzoyl, $\mathrm{R}^{2}=\mathrm{R}^{4}=\mathrm{H}$ & $\mathbf{2 3 a}, 78$ & \\
4 & $\mathrm{R}^{1}=$ phenyl, $\mathrm{R}^{3}=$ benzyloxycarbonyl, & $\mathbf{1 a}, 71$ & $\mathbf{2 6 b}, 75$ \\
& $\mathrm{R}^{2}=\mathrm{R}^{4}=\mathrm{H}$ & \\
5 & $\mathrm{R}^{1}=$ phenyl, $\mathrm{R}^{2}=\mathrm{H}$, & acetophenone, 77 \\
& $\mathrm{R}^{3} \mathrm{R}^{4}=1-$ phenylethylidenyl & \\
$6^{\mathrm{c}}$ & $\mathrm{R}^{1}=\mathrm{R}^{3}=$ phenyl, $\mathrm{R}^{2}=\mathrm{H}, \mathrm{R}^{4}=$ methyl & $\mathbf{1 a}, 71$ & $\mathbf{1 9 a}, 84$ \\
$7^{\mathrm{c}}$ & $\mathrm{R}^{1}=\mathrm{R}^{3}=\mathrm{R}^{4}=$ phenyl, $\mathrm{R}^{2}=\mathrm{H}$ & $\mathbf{1 5 a}, 76$ \\
$8^{\mathrm{c}}$ & $\mathrm{R}^{1}=\mathrm{R}^{3}=$ phenyl, $\mathrm{R}^{2}=\mathrm{H}, \mathrm{R}^{4}=$ allyl & $\mathbf{1 a}, 78$ & $\mathbf{1 a}, 76$ \\
$9^{\mathrm{c}}$ & $\mathrm{R}^{1}=\mathrm{R}^{3}=$ phenyl, $\mathrm{R}^{2}=\mathrm{H}, \mathrm{R}^{4}=$ benzyl & $\mathbf{1 a}, 75$ & $\mathbf{1 1 a}, 83$ \\
\hline
\end{tabular}

${ }^{a}$ Reaction conditions: solvent $=\mathrm{CH}_{2} \mathrm{Cl}_{2} / \mathrm{Et}_{2} \mathrm{O}=4: 1(\mathrm{v} / \mathrm{v}, 20 \mathrm{~mL})$, hydrazine $/ \mathrm{TiCl}_{4} / \mathrm{Mg}$ ratio = 1:4:10, r.t., $2-6$ h. $^{b}$ Yield of isolated product. ${ }^{\mathrm{c}} 35^{\circ} \mathrm{C}, 4-6 \mathrm{~h}$.

The N,N bond in hydrazone could also be cleaved under these conditions giving the corresponding amine and carbonyl compound in good yields (Table 3, entry 5). A similar situation was encountered with trisubstituted hydrazines, and they did not react completely in THF. However, the reduction of trisubstituted hydrazines took place smoothly when performed 
in the mixture solvent of $\mathrm{CH}_{2} \mathrm{Cl}_{2} / \mathrm{Et}_{2} \mathrm{O}(4: 1, \mathrm{v} / \mathrm{v})$ at $35{ }^{\circ} \mathrm{C}$ with a hydrazine/ $/ \mathrm{TiCl}_{4} / \mathrm{Mg}$ molar ratio of 1:4:10 (Table 3, entries 6-9). However, the observation was not surprising since it has been well documented in the literature that low-valent titanium reagents prepared in different solvents may exhibit distinct activity. ${ }^{27}$

\section{Conclusions}

In summary, we have established an efficient method for the reduction of hydrazines to the corresponding amines under mild conditions by using a low-valent titanium reagent conveniently prepared in situ from $\mathrm{TiCl}_{4}$ and $\mathrm{Mg}$ powder. The reaction solvent and hydrazine/ $\mathrm{Mg} / \mathrm{TiCl}_{4}$ molar ratio affected the reaction significantly. While acylhydrazines and trisubstituted hydrazines were found to be reduced efficiently in a solvent mixture of $\mathrm{CH}_{2} \mathrm{Cl}_{2}-\mathrm{Et}_{2} \mathrm{O}$ with a hydrazine/ $\mathrm{Mg} / \mathrm{TiCl}$ molar ratio of 1:4:10, tetrasubstituted hydrazines were reduced with a hydrazine $/ \mathrm{Mg} / \mathrm{TiCl}_{4}$ molar ratio of 1:4:10 in THF. Other hydrazines were reduced in THF with a hydrazine $/ \mathrm{Mg} / \mathrm{TiCl}_{4}$ molar ratio of $1: 0.4: 2.5$. The reaction was compatible with common functionalities such as chloride, methoxyl, ester, acyl, and C,C double bond, benzyl-nitrogen bond and benzyloxyl groups, providing a variety of amines in good to excellent yields.

\section{Experimental Section}

General. All reagents were purchased from commercial suppliers and were used without further purification. THF and diethyl ether were freshly distilled from Na/benzophenone and DCM was distilled from $\mathrm{CaH}_{2}$. Hydrazines used in this study were prepared following the literature procedures (see Supplementary Information). Column chromatography was performed with silica gel (200-300 mesh). Thin layer chromatography was carried out using Merck silica gel GF254 plates. NMR spectroscopy was performed on a Bruker (400 MHz or $600 \mathrm{MHz}$ ) spectrometer using TMS as an internal standard. GC-MS were made on an Agilent Technologies 6890-5973N GC-MS spectrometer with EI ionization at $70 \mathrm{eV}$. MS analyses were made on a Bruker Daltonics Bio TOF-Q Mass Spectrometer using ESI or MALDI-TOF ionization. All products are known and were characterized by comparing ${ }^{1} \mathrm{H}$ and ${ }^{13} \mathrm{C}$ NMR spectroscopic data with data reported in the literature. ${ }^{26}$

General procedure for the reduction of hydrazines to amines with low-valent titanium reagent in $\mathbf{T H F}$. $\mathrm{TiCl}_{4}(0.44 \mathrm{~mL}, 4 \mathrm{mmol})$ was added dropwise with a syringe to a stirred mixture of $\mathrm{Mg}$ powder $(0.6 \mathrm{~g}, 25 \mathrm{mmol})$ in dry $\mathrm{THF}(100 \mathrm{~mL})$ at $0{ }^{\circ} \mathrm{C}$ under an argon atmosphere. The resulting mixture was allowed to warm to ambient temperature and stirred for 2 h. Hydrazine $(10 \mathrm{mmol})$ in THF $(25 \mathrm{~mL})$ was then added and the mixture was stirred at ambient temperature for another $2-6 \mathrm{~h}$. The resulting solution was made alkaline by addition of saturated 
aqueous $\mathrm{NaHCO}_{3}$ solution and filtered through celite. The filtrate was extracted with $\mathrm{CH}_{2} \mathrm{Cl}_{2}$ repeatedly. The organic phases were combined and dried with $\mathrm{MgSO}_{4}$. The solvent was evaporated and the residue was purified by column chromatography on silica gel using $\mathrm{CH}_{2} \mathrm{Cl}_{2}$ and petroleum ether as eluent to give amines.

For tetrasubstituted hydrazines, $\mathrm{TiCl}_{4}(4.4 \mathrm{~mL}, 40 \mathrm{mmol})$ and $\mathrm{Mg}$ power $(2.4 \mathrm{~g} .0 .1 \mathrm{~mol})$ was added, and after addition of hydrazine, the mixture was stirred at $60{ }^{\circ} \mathrm{C}$ instead.

General procedure for the reduction of hydrazines to amines with low-valent titanium reagent in $\mathbf{C H}_{2} \mathbf{C l}_{2}-\mathbf{E t}_{2} \mathbf{O}$. $\mathrm{TiCl}_{4}(0.88 \mathrm{~mL}, 8 \mathrm{mmol})$ was added slowly with stirring to a mixture solvent of $\mathrm{CH}_{2} \mathrm{Cl}_{2}$ and $\mathrm{Et}_{2} \mathrm{O}(20 \mathrm{~mL}, 4: 1, \mathrm{v} / \mathrm{v})$, and lots of yellow precipitates were produced. Magnesium powder $(0.48 \mathrm{~g}, 20 \mathrm{mmol})$ was then added under Ar and stirring was continued for $2.5 \mathrm{~h}$ at room temperature. The yellow mixture turned black gradually. Hydrazine $(2 \mathrm{mmol})$ in $\mathrm{CH}_{2} \mathrm{Cl}_{2}(5 \mathrm{~mL})$ was added at room temperature and the mixture was stirred for another $2-6 \mathrm{~h}$ at room temperature for acylhydrazines, or at $35{ }^{\circ} \mathrm{C}$ for trisubstituted hydrazines. The resulting solution was made alkaline with saturated $\mathrm{NaHCO}_{3}$ solution and filtered through celite. The filtrate was extracted with $\mathrm{CH}_{2} \mathrm{Cl}_{2}$ repeatedly. The combined organic phases were dried with $\mathrm{MgSO}_{4}$. After removal of the solvent, the residue was purified by column chromatography on silica gel using $\mathrm{CH}_{2} \mathrm{Cl}_{2}$ and petrum ether as eluent to give amines.

\section{Acknowledgements}

We thank the Natural Science Foundation of China (21021001, 21072134 and J1103315/J0104) and the Analytical \& Testing Centre of Sichuan University for NMR and MS measurements.

\section{References}

1. Ricci, A. Modern Amination Methods, Wiley, New York, 2000.

2. Hinman, R. L. J. Org. Chem. 1957, 22, 148.

DOI: $10.1021 /$ jo01353a013

3. Feuer, H.; Brown, F. J. J. Org. Chem. 1970, 35, 1468.

DOI: $10.1021 /$ jo00830a045

4. Denmark, S. E.; Nicaise, O.; Edwards, J. P. J. Org. Chem. 1990, 55, 6219.

DOI: 10.1021/jo00312a034 
5. Alonso, F.; Radivoy, G.; Yus, M. Tetrahedron 2000, 56, 8673.

DOI: $10.1016 / S 0040-4020(00) 00797-3$,

6. Fernández, R.; Ferrete, A.; Lassaletta, J. M.; Llera, J. M.; Monge, A. Angew. Chem., Int. Ed. 2000, 39, 2893.

DOI: $10.1002 / 1521-3773(20000818)$

7. Fernández, R.; Ferrete, A.; Llera, J. M.; Magriz, A.; Martín-Zamora, E.; Díez, E.; Lassaletta, J. M. Chem. Eur. J. 2004, 10, 737.

DOI: $10.1002 /$ chem.200305501

8. Friestad, G. K.; Ding, H. Angew. Chem., Int. Ed. 2001, 40, 4491.

DOI: 10.1002/1521-3773(20011203)

9. Enders, D.; Funabiki, K. Org. Lett. 2001, 3, 1575.

DOI: $10.1021 / \mathrm{ol} 015869 \mathrm{~g}$

10. Ding, H.; Frestad, G. K. Org. Lett. 2004, 6, 637.

DOI: $10.1021 / \mathrm{ol} 036480 \mathrm{r}$

11. Sapountzis, I.; Knochel, P. Angew. Chem., Int. Ed. 2004, 43, 897.

DOI: 10.1002/anie.200353241

12. Sinha, P.; Kofink, C. C.; Knochel, P. Org. Lett. 2006, 8, 3741.

DOI: $10.1021 / \mathrm{ol} 801390 \mathrm{~h}$

13. Li, W.; Liu, X.; Hao, X.; Hu, X.; Chu, Y.; Cao, W.; Qin, S.; Hu, C.; Lin, L.; Feng, X. J. Am. Chem. Soc. 2011, 133, 15268.

DOI: $10.1021 /$ ja2056159

14. Brandes, S.; Niess, B.; Bella, M.; Prieto, A.; Overgaard, J.; Jøgensen, K. A. Chem. Eur. J. 2006, 12, 6039

DOI: $10.1002 /$ chem.200600495, and references cited therein.

15. Deniau, E.; Enders, D. Tetrahedron 2001, 57, 2581.

DOI: $\underline{10.1016 / S 0040-4020(01) 00073-4}$

16. Bataille, P.; Paterne, M.; Brown, E. Tetrahedron: Asymmetry 1999, 10, 1579.

DOI: $\underline{10.1016 / S 0957-4166(99) 00146-9}$ 
17. Miyabe, H.; Ueda, M.; Nishimura, A.; Naito, T. Org. Lett. 2002, 4, 131.

DOI: $10.1021 / \mathrm{ol017013h}$

18. Shono, T.; Kise, N.; Fujimoto, T.; Yamanani, A.; Nomura, R. J. Org. Chem. 1994, 59, 1730. DOI: $10.1021 /$ jo00086a023

19. Enders, D.; Teschner, P.; Raabe, G. Heterocycles 2000, 52, 733.

DOI: $10.3987 / C O M-99-8813$

20. Enders, D.; Wallert, S. Synlett 2002, 304.

DOI: $10.1055 / \mathrm{s}-2002-19766$

21. Casarini, M.; Gheli, F.; Libertini, E.; Pagnoni, U.; Parsons, A. Tetrahedron 2002, 58, 7925. DOI: $10.1016 / S 0040-4020(02) 00914-6$

22. Chaveau, A.; Martens, T.; Bonin, M.; Micouin, L.; Husson, H. P. Synthesis 2002, 1885. DOI: $10.1055 / \mathrm{s}-2002-33914$

23. Enders D.; Díez, E. J. Org. Chem. 1999, 64, 6329.

DOI: $10.1021 /$ jo990503r

24. Yamazaki, N.; Kibayashi, C. Tetrahedron Lett. 1997, 38, 4623.

DOI: $10.1016 / S 0040-4039(97) 00991-X$

25. Tang, Q.; Zhang, C.; Luo, M. J. Am. Chem. Soc. 2008, 130, 5840.

DOI: $10.1021 /$ ja711153b

26. Zhang, Y.; Tang, Q.; Luo, M. Org. Biomol. Chem. 2011, 9, 4977.

DOI: $10.1039 / \mathrm{c} 1 \mathrm{ob} 05328 \mathrm{k}$ 